\title{
Violencia y género: cuerpos vulnerables, vidas precarias y resistencia en las cartas de Mari
}

\author{
- María Rosa Oliver y Luciana Urbano \\ Centro de Estudios sobre Diversidad Cultural, Universidad Nacional de Rosario, Argentina
}

Fecha de recepción: 5 de mayo de 2020. Fecha de aceptación: 1 de junio de 2020.

\begin{abstract}
Resumen
El objetivo de este trabajo es ahondar en las formas de violencia ejercidas sobre las mujeres desde las fuentes paleobabilónicas de Mari (1775-1762 a.n.e.). Este corpus documental posee una nutrida "correspondencia femenina", allí las mujeres están presentes por doquier, las de la elite en especial, pero también otras de sectores subalternos, las servidoras de las reinas y princesas, las esclavas, las mujeres del común. Todas ellas están atravesadas, aunque de maneras diferentes, por los mecanismos masculinizantes del poder que las posicionan en lugares de acatamiento de la norma, extremando la vulnerabilidad de sus cuerpos, hacinándolas en una precariedad que en muchos casos pone sus vidas en peligro. Nuestro objetivo es abordar esos múltiples mecanismos de violencia sin desconocer las jerarquías de clase y las posibilidades de resistencias y solidaridades. Si bien es cierto que las concepciones sobre violencia de género son muy actuales, nos parece pertinente historizar la violencia y revisitar las fuentes antiguas desde esta perspectiva.
\end{abstract}

Palabras clave: género, violencia, resistencias, paleobabilónico, Mari

Violence and Gender: Vulnerable Bodies, Precarious Lives and Resistance in the Mari Letters

\begin{abstract}
The aim of this article is to delve into the forms of violence exerted on women from the Old Babylonian sources of Mari (1775-1762 BCE). This documentary corpus has a large "feminine correspondence" where women are present everywhere, those of the elite in particular, but also others from subaltern sectors, such as the servants of queens and princesses, slaves, women of the
\end{abstract}


common. All of them are crossed, although in different ways, by the masculinizing mechanisms of power that position them in places of compliance with the norm, increasing the vulnerability of their bodies, crowding them into a precariousness that in many cases puts their lives in danger. Our objective is to tackle these multiple mechanisms of violence without ignoring class hierarchies and possibilities of resistance and solidarity. Although it is true that conceptions of gender violence are very current, it seems pertinent to us to historicize violence and revisit ancient sources from this perspective.

Keywords: gender, violence, resistance, Old Babylonian, Mari

\section{Introducción}

Este artículo desarrolla una propuesta teórico-metodológica de relectura de las fuentes antiguas abrevando en los estudios de género, en los aportes de la historia social y las interpretaciones ligadas al poder, entre otros referentes teóricos. De acuerdo con Beatriz Garrido (2004: 1), consideramos que a partir del análisis de la producción actual, tanto historiográfica como de otras disciplinas sociales, en las que emergen los cuestionamientos que desde el feminismo se han realizado al paradigma androcéntrico, es posible realizar una mirada crítica en torno a la cuestión de los géneros que desmitifique al sujeto racional masculino. En esta dirección, los estudios de las relaciones de género -cruzadas por un entramado de relaciones de poder- se dirigen a develar las representaciones de género, la dinámica de la interacción social e individual, así como la significación de la sexualidad en diferentes culturas y períodos históricos. En ese sentido es que nos permitimos poner en tensión concepciones actuales que nos posibilitan interpelar testimonios del pasado para reconocer la especificidad de las relaciones de género en su propio contexto histórico. Se considera que, una de las maneras de percibir el ejercicio del poder es la forma en que se dispone de los cuerpos femeninos. Estos estilos son diversos y dan entidad a las "estructuras elementales de la violencia" que pretendemos desentrañar. ${ }^{1}$

De esas múltiples formas de sujeción y control sobre el cuerpo de las mujeres y su descendencia hemos seleccionado dos: la política matrimonial llevada adelante por Zimri-Lim ${ }^{2}$ y la apropiación de las mujeres de la casa de los reyes vencidos en tanto botín de guerra. ${ }^{3}$ Por lo tanto, además de considerar las

\footnotetext{
1 Ver apartado sobre los conceptos operativos en Segato (2003).
}

2 Es pertinente aclarar que la práctica de las alianzas matrimoniales interdinásticas no fue exclusiva del reino de Mari. Muy por el contrario fue una estrategia común y sumamente extendida. Sabemos que Hammurabi se casó con una hija del rey de Ešnunna y tal vez con una princesa de Mari (Lafont, 2001: 313). También pueden verse para el caso neo-asirio Svärd (2012, 2015); para el periodo de Ur III ver Michalowski (1976, 1978, 1982). Para Egipto, el período mejor documentado es el de El Amarna (1400-1300 a.n.e.), ver Podany (2010: 217-42).

3 Esta práctica de apropiación de las mujeres de la casa del vencido estaba sumamente instalada en aquella sociedad, a tal punto que el nuevo rey mariota reutilizó a su favor la alianza celebrada por Yasmah-Addu con Qațna incorporando a Dâm-hurâși como su 
formas y disfraces en que se presenta la violencia sobre un universo femenino heterogéneo, consideramos que esta dominación no imposibilitó que las mujeres llevaran adelante prácticas que podrían ser pensadas como atisbos de resistencias.

De entre todos los casos que nos provee la rica documentación mariota, ${ }^{4}$ hemos seleccionado el que evidencia los vínculos entre Mari y la ciudad de Ašlakkâ al norte de la alta Mesopotamia en la región denominada Ida-Maraș, y nos detendremos en dos momentos históricos muy precisos. No obstante, nuestra mirada a través de la mirilla del caso seleccionado, no nos impedirá visibilizar a otras mujeres, algunas de ellas miembros de la elite y otras subalternizadas, sólo registradas mediante la voz de las primeras, como las esclavas y servidoras. ${ }^{5}$

reina principal (Durand, 2000: 295-298). El rey vencedor no necesitó ritualizar nuevamente la alianza a través del matrimonio, sino que la unión quedaba explícita a través del "derecho de herencia" que le otorgaba el triunfo. Asimismo su origen como hija de uno de los grandes reyes de la época y la esmerada atención que su matrimonio revistió para el reino de la Alta Mesopotamia, le otorgaron a Dâm-hurâși un prestigio tal que le permitió mantener su posición de reina principal durante todo el periodo. Ver Marello (1994); Ziegler (1999a, 1999b); Oliver (2008); Urbano (2016).

4 El $A R M$ I se publicó en 1950 y en la actualidad ya cuenta con más de 30 volúmenes. A partir de la década de 1980, Jean Marie Durand tomó a su cargo la publicación de los textos y les dio una orientación más temática. A su vez, Durand corrigió y re-tradujo los tomos de los ARM hasta 1998 y los editó en tres volúmenes dentro de la colección Littératures anciennes du Proche Orient (LAPO vols. 16, 17 y 18). También debemos destacar la edición de la serie Florilegium Marianum con XIV tomos hasta el 2014, donde también se han publicado fuentes por fuera de los $A R M$. No obstante, aún quedan muchas fuentes por publicar, tarea que sigue estando en manos del equipo francés reunido en el Collège de France. Asimismo, un interesante proyecto liderado por Dominique Charpin y el equipo del Institut du Proche-Orient Ancien en el Collège de France, denominado ARCHIBAB (www.archibab.fr), actualmente permite el acceso on-line a parte de los archivos de Mari y de otros sitios del periodo Paleobabilónico. Por su parte, contamos con dos ediciones de las fuentes en inglés, la de Heimpel (2003) y la más reciente edición de Jack Sasson (2015). Aquí se siguen las ediciones ARM y LAPO salvo se indique lo contrario. La antigua ciudad de Mari (Tell Hariri, actual Siria) fue descubierta fortuitamente en 1933 cuando unos beduinos cavaban una tumba en el sitio ubicado en la actual Siria cerca de la frontera sudeste con Iraq. Como en ese momento Siria estaba bajo mandato francés, se convocó al arqueólogo André Parrot para que se pusiera al frente de la excavación y las tablillas fueron llevadas prontamente a la ciudad de París, puntualmente al Museo del Louvre, para ser estudiadas por epigrafistas con el compromiso de luego volver a Siria. Desde entonces se sucedieron más de cuarenta campañas, primero a manos de Parrot, luego desde 1979 a 2004 a cargo de Jean-Claude Margueron y en la actualidad de Pascal Butterlin, marcando una continuidad en los trabajos a cargo de equipos franceses, interrumpidos lamentablemente por los avatares políticos del mundo y de la región como sucedió en los últimos años.

5 El concepto de sujetos sociales subalternos/as está presente en los desarrollos de A. Gramsci y los estudios de subalternidad. Sin embargo, Gayatri Spivak (1998), una de las referentes más importantes y pionera de los estudios postcoloniales, con una fuerte impronta de J. Derrida y la deconstrucción como estrategia metodológica, nos interpela: ¿puede realmente hablar el individuo subalterno haciendo emerger su voz desde la otra orilla, inmerso en la división internacional del trabajo promovida en la sociedad 
En consonancia con lo sucedido en otras ciudades del Ida-Maraș, Zimri-Lim sellará una alianza de subordinación con el rey de Ašlakkâ, Ibâl-Addu, entregándole una de sus hijas en matrimonio: en el año ZL 7[6’] Inib-šarri llegará a la ciudad para ser la nueva reina. Cuando el matrimonio se concreta, con la consecuente circulación de dones y contra dones, la alianza se encuentra sellada y las princesas mariotas devenidas reinas en el extranjero se convierten en representantes de los intereses del rey procurando cumplir y hacer cumplir lo expresado en los acuerdos de subordinación.

Por supuesto los matrimonios de subordinación también implicaban el apoyo para la guerra. En el contexto de la invasión elamita al Ida-Maraș entre los años ZL 9[8'] y ZL 10[9'], la situación se volverá más aguda, marcando un hito en la relación entre los reyes. En este contexto el tema central de las cartas es el movimiento de tropas para hacer frente a los invasores. Para Ibâl-Addu la llegada de los elamitas parece haber sido la gota que colma el vaso para romper en hostilidades con el rey de Mari y desconocerlo como "su señor". Las dificultades en esta relación también permean las cartas de Inib-šarri. Pese a los intentos de Zimri-Lim por retener a su hija en Ašlakkâ, los motivos políticos complejizaron y dificultaron la relación entre los dos Estados y el matrimonio acabó disolviéndose para finales del reinado. En el año ZL 12 [11'] el rey de Mari partirá en una campaña militar para conquistar la ciudad, depondrá a Ibâl-Addu y se apoderará de las mujeres de su palacio y de numerosos artistas y especialistas. En este contexto, el botín de guerra es considerado como un aporte regular de mano de obra, mayoritariamente femenina empleada en los talleres textiles (Limet, 1995: 178).

La guerra se constituye en el mayor proveedor de fuerza de trabajo y nos muestra la vulnerabilidad de las mujeres de la elite vencida y en general. El núcleo central pasa por la redistribución del botín y los lugares asignados a las prisioneras y bajo qué condiciones. Esta reflexión circula en torno a las principales afectadas dentro de esa política, puesto que las mujeres constituían la parte más importante del botín de guerra. Es una presunción fuerte que estas formas estaban establecidas y naturalizadas por diferentes prácticas instituidas. Como ha expresado Rita Segato (2016: 63), las mujeres siempre fueron tratadas "como botín de guerra, el premio de la victoria, el objeto sexual de los soldados". En el contexto bélico el cuerpo femenino "ha estado imbuido de significado territorial. El destino de los cuerpos femeninos, violados e inseminados en las guerras de todas las edades dan testimonio de ello" (Segato, 2016: 70).

capitalista, dentro y fuera del circuito de la violencia epistémica de una legislación imperialista y de programa educativo que viene a complementar un texto más temprano? La autora nos aclara que la imposibilidad de hablar no es porque sea mudo sino porque el subalterno no ha dejado huellas que puedan ser recuperadas para producir una contrahistoria: carece de posición desde la cual poder hablar y convertirse en sujeto. En el caso de las mujeres, la posibilidad de recuperación de un sujeto (sexualmente) subalterno aparece una vez más en un estado de pérdida y de sobre-determinación. Esta asimetría legalmente programada en el estatuto del sujeto que efectivamente define a la mujer como objeto de un marido, opera obviamente llevando agua para el molino del status simétricamente legal del sujeto masculino. Ver Spivak (1998); Bidaseca (2018). 
Estos dos momentos históricos, la concreción de la alianza matrimonial y la toma de la ciudad a finales del reinado de Zimri-Lim nos han legado una importante cantidad de fuentes y en ellas podemos visualizar formas de dominación sobre los cuerpos femeninos y también inferir estrategias de resistencia.

\section{Algunas reflexiones sobre las categorías teóricas}

Los conceptos son materiales imprescindibles en la caja de herramientas de las y los historiadores que se definen uno en función del otro, guiándonos en un espiral reflexivo sobre nuestro problema de investigación: cómo funcionaron las "estructuras elementales de la violencia" en la antigua ciudad de Mari, qué marcas dejó en los cuerpos femeninos ese discurso totalizante y asimismo qué posibilidades y qué tipo de resistencias y solidaridades podemos encontrar en una sociedad y en un tiempo muy distinto al nuestro.

La conceptualización de violencia y sus estructuras elementales nos remiten al texto de Rita Segato. El título de su libro alude a la célebre obra de Claude LéviStrauss (1993 [1949]), de la que se considera deudora porque le permite conectarse con "un esquema teórico útil para hablar de la mecánica de la violencia" (Segato, 2003: 254). De acuerdo con Segato, el fenómeno de la violencia emana de la relación entre dos ejes interconectados. Uno horizontal, formado por términos vinculados por relaciones de alianza o competición, y otro vertical, caracterizado por vínculos de entrega o expropiación. Estos dos ciclos se articulan formando un sistema único cuyo equilibrio es inestable, un sistema de consistencia deficiente. El ciclo cuya dinámica violenta se desarrolla sobre el eje horizontal se organiza ideológicamente en torno de una concepción de contrato entre iguales, es decir que corresponde a los trueques, a los dones y contradones, y el ciclo que gira sobre el eje vertical corresponde al mundo pre-moderno de estamentos y castas, justamente el de la conyugalidad y la primogenitura.

En ambos ejes, los miembros son portadores de índices diacríticos de su posición relativa. Como ha argumentado Carol Pateman (1995 [1988]), la esfera del contrato y la del estatus continúan su curso, como dos universos de sentido que, a pesar de tener raíces en tiempos diferentes, son coetáneos. El estatus introduce una inconsistencia en la modernidad, pero este elemento inconsistente obedece a una historia de larguísima duración y gran resistencia al cambio. El primero rige las relaciones entre categorías sociales o individuos que se clasifican como pares o semejantes. El segundo ordena las relaciones entre categorías que, como el género, exhiben marcas de estatus diferenciados, señas clasificatorias que expresan un diferencial de valor en un mundo jerárquico. Estas marcas son construidas y percibidas como indelebles. El eje vertical estaría marcado por los estratos, por las diferencias jerárquicas y por grados de valor, las relaciones son de exacción forzada, o de entrega de tributo, en su forma paradigmática, de género, el tributo es de naturaleza sexual (Segato, 2003: 253- 254). Como lo expresa Segato (2003: 146):

(...) es posible afirmar que el sistema no se reproduce automáticamente ni está predeterminado a reproducirse como consecuencia de una ley natural, sino que lo hace mediante un repetitivo ciclo de violencia, en su esfuerzo por la restauración 
constante de la economía simbólica que estructuralmente organiza la relación entre los estatus relativos de poder y subordinación representados por el hombre y la mujer como iconos de las posiciones masculina y femenina así como de todas sus transposiciones en el espacio jerárquico global (...).

Por otro lado, el concepto de "vulnerabilidad" es importante para nuestro análisis. Esta categoría ha estado largamente vinculada a las mujeres pero sin duda las excede, como nos explica Judith Butler (2017). Para esta autora, no podemos "entender la vulnerabilidad del cuerpo si no la enmarcamos dentro de las relaciones que este mantiene con otros seres humanos" (Butler, 2017: 132). Butler elabora así un concepto relacional de cuerpo, no es posible hablar del cuerpo sin referirnos a los complejos sistemas de interdependencia social que lo mantienen y lo condicionan desde el mismo momento de su nacimiento. En dicha interdependencia el cuerpo se expone, a la historia, a la precariedad, al poder, pero también al amor, solidaridad y amistad (Butler, 2017: 150). Y aunque todos los cuerpos son vulnerables, no es erróneo plantear que el cuerpo de las mujeres es de los más vulnerables, colocándolas en una posición de "precariedad" de sus vidas, de seres susceptibles de diferentes modalidades de violencia (Butler, 2010: 16). Asimismo la vulnerabilidad como inherente al cuerpo humano va de la mano de la resistencia, no como acto de fortaleza, sino más bien como ejercicio de solidaridad. Ahora bien, Butler se pregunta (de manera retórica, dando por entendido una respuesta afirmativa) " ¿acaso no estamos mostrando que somos seres precarios y a la vez actuantes?” (Butler, 2017: 155).

Para los estudios más tradicionales que podríamos considerar como neo-positivistas las resistencias femeninas no son posibles, sólo el acatamiento a la norma que es la dominación masculina. Por su parte, algunos estudios de género han tomado la resistencia como oposición abierta al patriarcado, como resultado de una conciencia de género empoderada que puede producir prácticas contra-hegemónicas. Estos planteos nos interpelan ¿cuál es el tipo de resistencia femenina posible en las sociedades que estamos investigando? Interrogante que nos acerca a los estudios feministas post-coloniales. A principios de los años '90, la antropóloga Lila Abu-Lughod, trabajando sobre las mujeres beduinas se preguntaba “ ¿cómo podemos reconocer los casos de resistencia llevados a cabo por mujeres sin que les atribuyamos erróneamente formas de conciencia o políticas que no son parte de su experiencia - algo así como una conciencia o unas políticas feministas?" (Abu-Lughod, 1990: 47). ${ }^{6}$ Reconstrucciones de este tipo caen entrampadas en lo que Abu-Lughod denomina la idealización de la resistencia, es decir buscar en la historia ejemplos de mujeres que se enfrentaron al poder patriarcal, casi como una forma romántica de buscar esperanzas en el pasado frente a un presente de dominación. La autora nos dice: "Al leer la resistencia de esta manera, colapsamos las distinciones entre diferentes clases de resistencias y repudiamos ciertas cuestiones que tienen que ver con los mecanismos del poder" (Abu-Lughod, 1990: 42).

Michel Foucault, especialmente en su Historia de la sexualidad, nos dice que "el poder no es algo que se adquiera, arranque o comparta, algo que se conserve o se deje escapar, el poder se ejerce a partir de innumerables puntos, y en el juego de relaciones móviles y no igualitarias (...)” (Foucault, 2008 [1976]: 90). 
También nos advierte que: "donde hay poder hay resistencia, y (...) ésta nunca está en posición de exterioridad respecto del poder (...) los puntos de resistencia están presentes en todas partes dentro de la red de poder (...) constituyen el otro término en las relaciones de poder; en ellas se inscriben como el irreductible elemento enfrentador" (Foucault, 2008 [1976]: 91-92). Abu-Lughod propone invertir esta fórmula, "donde hay resistencias hay poder" y no pensarlas como prácticas de exterioridad al poder sino como partes-de-y-en-el-poder, como uno de los efectos mismos del poder o en sus palabras como un "diagnóstico del poder" (Abu-Lughod, 1990: 42), posibilitándonos detectar cambios históricos en las configuraciones y los métodos del poder (Abu-Lughod, 1990: 48).

Se consideran las resistencias no como prácticas conscientes para enfrentarse a la dominación masculina sino como un efecto del poder mismo, como "actos reflejo" que no están fuera de la dominación masculina. Sin embargo, algunos de ellos generan verdaderos conflictos en la dinámica cotidiana de las relaciones de género. Como nos dice Lila Abu-Lughod (1990: 53), "tenemos que aprender a leer en las diversas formas de resistencias locales y cotidianas la existencia de una variedad de estrategias y estructuras de poder específicas. La atención a las formas de resistencia en sociedades concretas puede ayudarnos a ser críticos con las teorías del poder parciales o reduccionistas" (nuestro énfasis). En tal sentido Saba Mahmood (2010: 66) nos dice: "en las dos últimas décadas, una cuestión ha ocupado a muchos teóricos feministas: ¿ de qué manera la cuestión de la especificidad histórica y cultural debería ser incorporada tanto en los análisis como en las políticas de cualquier proyecto feminista?". Para nosotras la pregunta es cómo construir categorías útiles desde el género para nuestra especificidad histórica descolonizando los archivos y las reconstrucciones androcéntricas.

Las fuentes seleccionadas nos ofrecen un abanico de situaciones en las cuales la violencia se manifiesta. Se considera especialmente la vulnerabilidad de las mujeres en su condición de botín de guerra, las esclavas sólo atisbadas de manera indicial, las mujeres enfermas, las ancianas, las servidoras de las mujeres de elite y también las que eran parte de las familias reales. Las resistencias en esta sociedad, en el sentido que planteamos más arriba, tienen características muy particulares que es necesario visibilizar como un universo complejo de tensiones y negociaciones.

\section{Vulnerabilidad inscrita en el cuerpo de las mujeres y atisbos de resistencia elusiva}

Inib-šarri tuvo un matrimonio breve con el rey de la ciudad de Zalluhan y antiguo mer $^{\prime} m^{7}$ bensimalita. ${ }^{8}$ A la muerte del rey después de una enfermedad,

7 El sentido de esta palabra es "jefe de pasturas". Este era un funcionario nombrado directamente por el rey que controlaba al elemento nómade que formaba parte del estado mixto (gentilicio y territorial) que Di Bennardis (2013: 30) identificó en la ciudad de Mari. Para una explicación detallada del rol del "jefe de pasturas" ver Fleming (2004: 76-85). Sobre la discusión respecto del problema amorreo ver la excelente puesta al día de Michalowski (2011: 82-121) y Verderame (2013).

8 El matrimonio se realiza en el año ZL 3[4'] según Guichard (2009: 21). 
Inib-šarri no sólo debe enfrentar el duelo sino que además se encuentra acorralada por los enemigos de su difunto marido, por lo cual debe ser rescatada por soldados mariotas y alojada en Nahur, un sitio cercano a Ašlakkâ:

LAPO 18, 1246 [ARM X, 79] ${ }^{9}$

Cuando Zakura-abum enfermó, le escribí a mi Señor, y ahora que él está muerto y yo no he podido llorarlo ni quince días. Se me ha hecho salir de la ciudad y he partido a Nahur.

Sin embargo los deseos de Inib-šarri de volver a Mari se desvanecen rápidamente pues su padre le solicita que rápidamente se dirija a Ašlakkâ para casarse con el rey de esa ciudad, antiguo rival de su difunto marido. Tras algunas tratativas sobre el terhatum ${ }^{10}$ y un especialista vinculado a la producción de miel y vino, el nuevo matrimonio con Ibâl-Addu se realiza durante el transcurso del año ZL 6[7'] (Guichard, 2009: 23). Este caso muestra claramente la disposición que el padre tiene sobre el cuerpo de su hija, la cual le permite socializarlo en función de sus necesidades. ${ }^{11}$

A finales del reinado, la alianza matrimonial se debilita en paralelo a la relación política, Ibâl-Addu confina a Inib-šarri a Nahur (ver LAPO 18, 1243 [ARM $\mathrm{X}, 76]$ ). La situación en su nueva residencia no es propia de una reina, pasa necesidades y está socialmente relegada. Con la intención de que la situación política no se complejice aún más Zimri-Lim le solicita que vuelva al palacio, ella obedece mostrándose leal a su padre:

ARM X, 74

Di a mi señor: así habló Inib-šarri, tu servidora

He escrito al menos 2 veces a mi Señor a propósito de mis agravios. Él me ha respondido: “¡Vamos! ¡Entra en Ašlakkâ; no desobedezcas! ¡Vamos!” He aquí lo que él me ha escrito.

Ahora, he entrado en Ašlakkâ y tengo todavía más motivos de desengaño. ¡La esposa de Ibâl-Addu, ella sola, es reina; y los presentes de la ciudad de Ašlakkâ y de las diferentes ciudades, siempre son recibidos por esta mujer! En cuanto a mí, él me ha dejado viviendo en un rincón, y me ha hecho mantener las mejillas en mis manos como una tonta. ${ }^{12}$ Siempre delante de la mujer, su esposa, toma

9 Las fuentes han sido traducidas del francés por las autoras.

10 El terhatum es "la parte entregada como garantía de constitución de la alianza matrimonial o afianzamiento de la misma, tradicionalmente considerado como el 'precio de la novia'" (Oliver, 2009: 126). Una vez que la familia de la novia recibe el terhatum, el compromiso es definitivo. En general es un monto inferior al de la nidittum o seriqtum, "dote" que la novia recibe de su propia familia y que luego será transmitida a sus hijos. Además, el novio envía el biblum a la novia y su familia como regalos personales para la boda. Ver Westbrook (1988: 278-284); Oliver y Ravenna (1999); Laffont (2001).

11 En el año ZL 8 [7'], Inib-šarri vuelve a la casa de su padre justo en el mismo año en que él realiza un viaje por el noreste del Habur hasta Hušla (Charpin y Ziegler, 2003). Luego de esta ausencia de su residencia matrimonial, Inib-šarri no quiere regresar a Ašlakkâ, lo que evidencia ya la presencia de dificultades al interior del matrimonio.

12 Disponemos varias traducciones sobre esta carta. Las discrepancias más significati- 
su alimento y su bebida.

Siempre, mis ojos lloran; además, mi boca está hambrienta. Él acaba de reforzar su guardia sobre mí.

Otra cosa: el nombre de mi Señor es muy fuerte, pero yo, aquí, no soy más que un sujeto ignorado: no he recibido el recipiente ni los dos vasos de lujo (gal) de oro que mi señor me ha enviado al retorno de Ibâl-Addu; él no me ha dado los recipientes ni esos vasos de lujo. ¡Si él ama la persona de mi Señor, entonces él me necesitará, ${ }^{13}$ a mí, tu servidora!

[Laguna] Él se comporta tal como un enemigo de mi Señor. Hace falta que mi Señor me envíe sus servidores para devolverme a él, de manera que vuelva a ver su rostro.

Como podemos ver, Inib-šarri no puede eludir el peso que el mandato le impone; pero las quejas no cesan. La joven reina no ocupa el lugar que le fue prometido y que reclama en tanto hija de Zimri-Lim. Inib-šarri es plenamente consciente de la importancia de su jerarquía y destaca que su marido la necesita para legitimar su posición en la corte de Ašlakkâ. La carta se cierra acusando a Ibâl-Addu de traición para con su padre y solicitando "volver a Mari”. Durante su residencia en Nahur, Inib-šarri escribe a su padre solicitándole volver a Mari.

LAPO 18, 1244 [ARM II, 113]

Di a mi señor: así habló Inib-šarri, tu servidora

[...] Entonces, él me ha hecho entrar en Nahur en mi vivienda de viaje.

Desde el día que dejé a mi Señor, estoy privada de alimento y bebida caliente. ¡La

sucesión de acontecimientos se ha vuelto peor que antes! Acepto que mi Señor

vas son sobre las líneas 19-20. Durand (2000: 464-465; LAPO 18, 1242) la traduce como: "Quant à moi, il m’a placée ma résidence dans le harem". Es puntualmente sobre traducir la palabra tubqum como harén que se han planteado las diferencias. Durand (1997: 82) plantea que el significado es rincón y remite a un espacio interno y cerrado. En Durand y Margueron (1980: 260-263) analiza una serie de casos en donde tubqum remite a espacios internos de una casa. Esa asociación directa no nos parece pertinente. Posteriormente Jack Sasson (2015: 116) tradujo la carta en cuestión de la siguiente manera: "As for me, she/he has set me in a corner". Sostenemos que utilizar conceptos propios de otra realidad histórica sin cuestionar su pertinencia puede conducir a una suerte de "comodidad intelectual": hablamos de harén porque inmediatamente nos conduce a una serie de imágenes sobreentendidas por todos y así no sería necesario aclarar más ni detenerse a conceptualizar críticamente. Sin embargo, esta opción no aporta sino a recrear los estereotipos que velan el rol protagónico de las mujeres en la antigüedad oriental y además abonan peligrosamente las fantasías de encontrar en el "exótico" y lejano pasado oriental mujeres definidas por los atributos ideales del patriarcado: dóciles, sumisas, siempre bellas, jóvenes y disponibles. Consideramos que no es suficiente encontrar un espacio privado dedicado a la sociabilidad femenina. Debemos encontrar relaciones sociales propias de la vida de harén, como la reclusión, el aislamiento, la inviolabilidad del espacio, la presencia de eunucos. La realidad histórica que nos dejan entrever la "correspondencia femenina", la arqueología y la arquitectura del palacio, no muestra un mundo muy alejado de ello. Ver Westenholz (1990); Solvang (2005); Lion (2007); Svärd (2015); Garcia-Ventura (2012); Oliver (2013); Urbano (2011, 2013, 2016).

13 Sobre este pasaje Durand se pregunta: "¿Qué sentido preciso se le puede dar aquí a hašâhum? Inib-šarri podría comparecerse de la falta de interés sexual de su esposo por ella" (Durand, 2000: 466: nota j). El significado más común de la palabra (verbo) es "necesitar", optamos por esta traducción. 
continúe en silencio, pero entonces, ique me vuelva a llevar! ¡Mi resentimiento es más grande que nunca! De hecho, ¿no es este punto un ultraje personal que él me hace? Ahora bien, ¿lbâl-Addu tuvo la misma audacia hacia el enemigo de mi señor? Por otro lado, iltûr-Asdû ha llegado!; ha escrito 3 veces sobre mi persona, de eso que él dice ilbâl-Addu no tiene cura!

LAPO 18, 1245 [ARM II, 112]

Di a mi señor: así habló Inib-šarri, tu servidora

¿Hasta cuándo me quedaré en Nahur? El pacto de no agresión fue instaurado.

Además el camino está libre. Hace falta que mi Señor escriba para que se me lleven.

Además, quiero ver el rostro de mi Señor de quien estoy privada.

Otra cosa: hace falta que mi Señor me haga llegar una respuesta a mi carta.

Podemos reconocer tres tópicos centrales en las cartas. Inib-šarri le demuestra a su padre que fue obediente haciendo lo que él le solicitaba, luego su esposo no cumplió con lo prometido y así justifica la necesidad de su vuelta a Mari. Por su parte, en la carta LAPO 18, 1244 [ARM II, 113], Inib-šarri es más precisa en su argumentación pues acusa a su esposo de ser débil con los enemigos de Zimri-Lim. Claramente está acusando a Ibâl-Addu de traición política para con su padre. Pero además, lo que estas cartas nos permiten identificar es cómo actúan las estructuras de dominación (del padre sobre la hija, del esposo sobre la esposa) revelando cómo se ejerce la violencia en su disposición sobre los cuerpos femeninos, así como también nos permiten visualizar las jerarquías intra-género entre una mujer afianzada en el poder sobre otra advenediza.

La ruptura definitiva de las relaciones entre Mari y Ašlakkâ tiene como motivo de fondo la invasión elamita al Ida-Maraș, como ya se ha mencionado. IbâlAddû, cansado de pedir auxilio y no ser escuchado, decidió virar en sus alianzas políticas para poder mantenerse en el poder. A finales del reinado de ZimriLim, aquel realiza una coalición con el rey de Eluhut contra la casa mariota. Inib-šarri rápidamente informa a su padre, quien para el invierno del año ZL 12[11'] parte en campaña militar hacia Ašlakkâ:

ARM X, 77

Di a mi señor: así habló Inib-šarri, tu servidora

Hace mucho tiempo, había escrito a mi Señor que Ibâl-Addu había situado su rostro hacia otro sitio. De hecho, aquello que he dicho de él está confirmado. Él declaró una plena amistad al príncipe de Eluhut.

¡Vamos! Mi Señor debe enviar a sus servidores para que ellos me vuelvan a llevar a él y que yo le diga a mi Señor todas las noticias que yo había informado. Si no, este individuo me maltratará con toda la hostilidad que pueda. Además esta noticia, la he escrito al menos dos veces a Itûr- Asdû.

Para principios de ZL 13[12'], Ibâl-Addû había sido derrotado. Su correspondencia, mujeres y artesanos fueron tomados por Zimri-Lim como botín de guerra. Frente a tales circunstancias lo más probable es que Inib-šarri haya logrado después de tantas súplicas volver a Mari. Este caso, que no es el único con estas características, nos permite inferir que frente a los efectos de la violencia las princesas supieron encontrar la forma de resistir. Si bien no es atinado pensar la posibilidad de que ellas pudieran rebelarse abiertamente contra la dominación masculina, creemos que a través de la figura de la disolución 
matrimonial pudieron encontrar un intersticio dentro de la ajustada malla de la dominación para resistir desde un lugar aceptado por la misma sociedad patriarcal. Cuando los reyes rompen el pacto de subordinación y se rebelan contra el poder mariota recrudeciendo la violencia sobre sus esposas, ellas no cesan de enviar cartas solicitando volver a Mari (ver Urbano, 2016, 2018; Oliver y Urbano, 2018). En el palacio de Mari ya no tendrían una posición tan destacada, tal vez la consecuencia del fracaso de sus matrimonios fue perder parte de sus prerrogativas.

En la correspondencia que el rey envía a sus colaboradores y a su esposa Šiptu luego de la toma de la ciudad se percibe que la mano de obra femenina constituye un importante caudal dentro del botín de guerra. Los términos acadios más comúnmente utilizados para referirse al botín de guerra son: šallatum y también šalalum. Estos implican no sólo bienes y objetos sino también personas. Para el asiriólogo Ignace Gelb (1973: 70-98), el término sumerio NAM-RA-AŠAG o el más común NAM-RA-AG, traducidos como botín, incluye personas y también objetos. Es decir que estaba constituido por bienes materiales, riquezas, sin embargo, una parte fundamental del mismo, eran los recursos humanos: tanto hombres como mujeres que en este período histórico son considerados como un bien preciado, pues la fuerza de trabajo en esta sociedad siempre era insuficiente. A las mujeres se les puede adjudicar un plus, el de crear más fuerza de trabajo a través de su fertilidad y además el atractivo de compartir el lecho de los vencedores. Zimri-Lim informa e instruye a su esposa Šiptu que se encuentra en Mari:

\section{LAPO 18, 1166 [ARM X, 126]}

Dile a Šibtu: así habla Zimri-Lim tu Señor

Aquí te envío las (mujeres que deban convertirse en) tejedoras. Entre ellas, hay sacerdotisas-ugbabtum. Identifica las sacerdotisas y remítelas al barrio de tejedoras.

Entre las tejedoras de aquí y las tejedoras de allá, elige entre ellas 30 o más si es posible, excelentes que no tengan el menor defecto desde la uña del pie hasta los cabellos de la cabeza, y envíalas a Warad-ili-šu ${ }^{14}$ para que les enseñe la orquesta, coros o música "subareana" (de Subur).

Por otra parte, se necesitará que sus apartamentos sean instalados en un lugar diferente. Vigila bien por sus raciones alimentarias para que su belleza no se altere. Por su parte, cuando tú hagas la elección entre las tejedoras, se necesitará que sea en presencia de Warad-ili-šu.

Además, da instrucciones a Mukannisšum ${ }^{15}$ para que la belleza del resto de las tejedoras que tú le confiarás, no se altere.

Una vez separadas las "músicas" por un lado, las otras, las no tan perfectas en su aspecto físico -según el canon de la época- eran devueltas al trabajo de la lana, la producción fundamental junto con el grano en la Mesopotamia antigua. El rey da las instrucciones en una secuencia de cartas que muestran el diseño imperante sobre los cuerpos femeninos y las tareas que les estaban

14 Jefe de música del palacio de Mari.

15 Funcionario del palacio encargado del tesoro y de distribuir las raciones. 
adjudicadas e incluso el reconocimiento sobre las consecuencias negativas de una distribución de raciones escasas entre las elegidas. La reina Šiptu, una de sus esposas con mayor jerarquía y capacidad en la toma de decisiones, podía participar de la elección pero tutelada por hombres de confianza del rey. En una misiva de Mukannišum al rey le manifiesta que:

LAPO 18, 1171 [XVIII, 21]

[...] sobre el botín que entró en Dêr (destinado a la diosa Dêrītum) (sea): 13 hombres, (x) mujeres, 2022 jovencitas, 16 muchachos, $x$ nodrizas, 5 tejedores (entre hombres y mujeres), 39 mujeres, 13 jovencitas, 10 muchachos, 7 nodrizas, tal es el conjunto que hice salir (el contingente que envió, mandó). 66 jovencitas son para el taller de tejido [...].

El funcionario distribuye y señala cómo se conforman los contingentes de trabajo y allí se visualizan entremezclados en un abigarrado montón hombres, mujeres, jóvenes y niños. Sin embargo sobresalen las mujeres, las jovencitas/jovencitos y otras mujeres con una función social muy importante en la Mesopotamia paleobabilónica: las nodrizas, las encargadas de nutrir a los infantes que eran una parte significativa en aquellos grupos. En este sentido la juventud y las posibilidades de reproducirse eran un plus entre las valoraciones de la mano de obra esclava o servil. Cuando envejecen su estima cambia, como nos dejan ver dos cartas del reinado anterior (Yasmah-Addu) en donde unas cantantes enviadas a cortes extranjeras son rechazadas por su edad. El rechazo puede deberse también a la negativa de querer incorporar a esas mujeres en su palacio, la mención de su identidad étnica (amorreos/benjaminitas) puede ir en tal sentido. De todas maneras creemos que identidad-edad no son elementos auto-excluyentes:
A. $979^{16}$
(...) a propósito de las mujeres amorritas que Samadahum ha enviado aquí, ellas son todas verdaderamente "frías" y viejas. No hay para mí entre ellas una sola mujer de verdad (...).
A. $3115^{17}$
(...) la mujer benjaminita, tu regalo, es vieja ¿Qué valor tiene ella? (...).

Esto se visualiza claramente en una fuente analizada por Katrien De Graff (1999: 18) sobre una transacción que genera un litigio: el caso de la esclava elamita y su bebé (sag géme elam.maki), vendidos por un haneo/suteo. Ante la huida de la joven esclava con su bebé, la madre de la esclava la suplanta, lo que produce una disconformidad manifiesta en el comprador ya que pierde la mano de obra joven y posibilidades futuras encarnadas en el bebé.

En otro caso informado por Erišti-Aya, hija de Zimri-Lim, mujer consagrada como nadìtum del templo de Sippar, realiza demandas y exigencias vinculadas 
a las esclavas domésticas. ${ }^{18}$ Reclama ofrendas de alimentos, ${ }^{19}$ aceites para la unción, plata o joyas y también hace explícito que parte de su dote la constituyen dos esclavas, que cuando se las enviaron, una llegó muerta por lo que requiere el envío de la otra con urgencia. En este caso la carta LAPO 18, 1202 (ARM X, 78) está dirigida a la reina, su madre o a otra de las esposas de su padre, aquí es notorio el tono beligerante de la misma:

LAPO 18, 1202 [ARM X, 78]

[...] Si se exceptúa la dote que tu esposo y tú misma me han permitido aportar al claustro (gagûm), es que [tendré que esperar que sean] los soldados los que me hagan el presente del próximo botín [redu-ú ša i-na šalatum] [...].

Aquí se puede visualizar otro sector social, el de las prisioneras de guerra que se van a convertir en esclavas domésticas ( $a m t \bar{u} m$ ) de una nadìtum. ${ }^{20} \mathrm{La}$ forma de percibir la existencia de las esclavas domésticas es a través de la correspondencia y los reclamos de alguien que pertenece al grupo privilegiado, en este caso Erišti-Aya. Sumemos otro caso donde las jerarquías de clase y la vulnerabilidad del cuerpo de las mujeres se dan de manera descarnada. Se trata de una esclava del palacio de Mari que enferma. La primera misiva es del rey, que se encontraba fuera del palacio, a Šiptu, la reina:

\section{LAPO 18, 1165 [ARM X, 130]}

(...) A propósito de Summudum, tema de tu carta, a causa de la enfermedad de esta mujer, de que numerosas mujeres van a enfermarse del mal de simmum. Es necesario que esta mujer habite en una habitación separada. iQue nadie la visite! Pero, si como yo temo, no se encuentra habitación separada de momento

18 Las naditum fueron consideradas por la historiografía como "sacerdotisas": Koschaker (1917), Driver y Miles (1952), entre otros, que aún continúan utilizando la denominación, e incluso tal consideración se remonta a Heródoto quien supone que eran prostitutas sagradas. Dentro de la reconstrucción histórica signada por el positivismo, el único lugar posible que podía ocupar una mujer con un cierto nivel de jerarquía era el de sacerdotisa o prostituta. Se puede convenir que la asociación con un gagûm, se convertía en una analogía muy conveniente para pensar el espacio especial que se percibe en las fuentes paleobabilónicas. Sin embargo, ni la idea de convento ni la de "monjas de clausura" con las que parece estar connotada la expresión claustro permiten comprender esta figura. La relación con el templo se presenta de una forma ambigua; la comprensión de las prácticas que se producían en el gagûm y la función de la nadītum se han visto enriquecidas por los planteos de Harris (1961, 1963, 1964, 1975), Stone (1982), contribuciones que permiten reparar en ella como "mujer naditum" con algunas particulares funciones y no como sacerdotisa ligada al ritual. El gagûm es definido por el CAD G: 10-11 como "edificio o sección del distrito del templo reservado a las mujeres nadītum". Para una actualización de las problemáticas relacionadas a la nadītum y del rol del gagûm, ver De Graef (2016, 2018a, 2018b); Lahtinen (2011); Barberon (2009, 2012); Stol (2016).

19 Según Durand (2000: 396) lo que reclama es similar a la ofrenda piqittu, que consistía generalmente en carne y harina, a veces también se agregaba pan y cerveza, debía ser entregada al templo de Šamaš, Ebabbar, en Sippar para los festivales de Šamaš, tanto por las nadītum como por los oficiales de la administración del gagûm.

20 Ver ARM X, 39. Para mayor comprensión sobre las esclavas domésticas, ver Seri (2011). 
y como los presagios concernientes a Summudum no son nada favorables, ¿por qué ocuparse de esta mujer? Que ella muera o que ella viva, las mujeres si no se enfermarán del mal de simmum. iQue esta mujer muera por lo tanto ella sola! (...).

La respuesta de la reina es muy clara. Remitiéndose posiblemente al veredicto de los médicos o adivinos, informa:

LAPO 18, 1163 [ARM X, 14]

(...) La mujer, si se la toca no vivirá más. Por ahora la hice habitar en los nuevos edificios. Ella toma su cerveza y su pan separadamente. Nadie debe acercarse a su cama o a su sitio [su presencia]. Es necesario que mi Señor llegue y haga lo que tenga que hacer (...).

Sólo podemos inferir que a la llegada de Zimri-Lim se decidirá sobre la muerte de esta mujer. La violencia adquiere aquí su formato más explícito.

Volvamos a las cartas que nos llegan de la toma de Ašlakkâ. El rey, sin embargo, no puede disponer de todas las mujeres. Algunas pocas privilegiadas podrán exceptuarse de ser dirigidas a los talleres del palacio o a los aposentos del monarca. La guerra, fuertemente vinculada con los aspectos ideológicos-religiosos, implicaba que si el rey ofendía a un dios con alguna de sus acciones, como en la siguiente carta, el reclamo no tardaba en llegar:

LAPO 18, 1169 [X123]

Dile a Sibtu: así habla tu Señor

No será necesario que al tomar algún rumor (noticia) tu corazón se preocupe [inquiete]. No hay nada que el enemigo pueda contra mí en el combate. Está todo bien, que nada inquiete tu corazón.

Además, es a causa de sus sacerdotisas que Addu [dios tutelar de la ciudad] de Kulmiš ha provocado el malestar [desorden, turbación] del cual me has hablado. Sobre la tablilla del botín que yo había hecho traer, las sacerdotisas de Kulmiš y las sacerdotisas de otros dioses habían sido inscriptas separadamente por individualidades, sobre la tablilla. ¡En efecto, que se identifiquen precisamente a las sacerdotisas de Kulmiš, para que ellas vuelvan a su casa! Revístelas de un hábito [vestido] y llévenlas en un carruaje tirado por mulas con 2 ruedas o sobre un carro tirado por mulas. Es necesario que los servidores que las han conducido [condujeron] desde allí mismo las traigan a buen puerto hacia mí. En más es necesario que ellas partan al mismo tiempo [conjuntamente hacia mí]. Hay una hija de Ibâl-Addu reténganla allá ino la devuelvan!

Se marca una diferencia entre la cuestión política y la ideológica-religiosa. La princesa, hija de Ibâl-Addu, no debe ser devuelta y se destaca la divergencia, siendo una princesa puede ser deportada; en el caso que fuera una sacerdotisa, tendrían que pensarlo más porque se puede ofender a los dioses (Durand, 2000: 354) y acarrear resultados desfavorables en el futuro. Las dificultades que podía provocar el disfavor de un dios acelera la devolución de las sacerdotisas. En la carta posterior se complejiza más la situación:

LAPO 18, 1170 [ARM X, 124]

Dile a Šibtu: así habla tu Señor 
En lo que concierne a la joven, hija de Ibâl-Addu, hija sagrada [consagrada], motivo de tu carta, se ha producido este rumor: "Es una sacerdotisa-ugbabtum de Addu". Ahora, lleva una encuesta [realizar una investigación, recabar testimonios] sobre esta joven hija con Wara-ili-šu. ${ }^{21}$ Si esta joven es una sacerdotisa de Addu y ella se lamenta [se queja], hazla salir (del palacio) y que ella se aloje en la casa de Ibâl-Addu.

Si por el contrario, ella no se lamenta [queja] que ella se aloje en el palacio y que la cuiden.

En el planteo del "rumor" podría estar presente una estrategia de resistencia. Podríamos inferir que la joven está apelando a la condición de sacerdotisa para evitar males mayores. Es evidente que la princesa es considerada como parte del botín de guerra, con un destino sellado al arbitrio del rey, pero su estrategia de aludir a su condición de consagrada a un dios, modifica el panorama. Para Jean-Marie Durand (2000:348) esto no sería una práctica femenina defensiva sino que el propio rey o el poder realiza la preservación para que no sufran las consecuencias a las que las somete el vencedor. El autor señala que hay que ir más allá de considerar el respeto por una hija consagrada sino que entran en juego otras cuestiones. Sin embargo, considera una anomalía la cantidad de sacerdotisas o mujeres consagradas a un dios dentro del palacio de Ibâl-Addu y sobre todo destaca cómo se pone en práctica este mecanismo con las reinas o mujeres de muy alta estirpe para hacerlas "escapar del derecho de guerra" con la consagración a una divinidad.

El matiz es ligero, sin embargo, nuestra mirada se acerca más a la idea de estrategias femeninas de resistencia, sin dejar de lado posibles prácticas entre adversarios para preservarlas, pactos masculinos en un mundo atravesado por la lógica de la guerra. Es posible que se implementaran ciertas tácticas, leves resquicios modificadores de lo instituido. Por supuesto, la condición social señalaba los límites de lo posible, no todas las mujeres serán protegidas, sólo algunas.

\section{Reflexiones finales}

En las fuentes analizadas se percibe hasta qué punto la organización socioeconómica y política descansaba sobre el dominio sobre la mujeres, incluso las que en un determinado momento de sus vidas habían ocupado espacios de poder. Nos propusimos comenzar a historizar la violencia en las relaciones de género en la sociedad de Mari. Las mujeres, o por lo menos las que salen a la luz en la correspondencia del período, y sus cuerpos eran vulnerables y vulnerados de acuerdo a la jerarquía social y a los avatares políticos que les tocaba enfrentar. Soportaban diversos tipos de violencia en sus distintos niveles desde la más explícita y directa hasta sus formas más enmascaradas, impuestas por usos y costumbres. En general, como se ha desarrollado, las involucradas son mujeres de la elite, de las familias reales destinadas a la política matrimonial y

21 Jefe de los músicos encargado del botín de mujeres que se recibía. 
las mujeres de la elite vencida. Sin embargo, y aunque es más difícil encontrarlas, están las que pertenecen a estratos sociales subalternos como las esclavas y servidoras del palacio, quienes sólo se hacen visibles en los intersticios del discurso de los y las involucrados en el ejercicio del poder.

Es cierto que también se encuentran estrategias y formas de resistencia que posibilitan reconocer no una subordinación aplastante, sino una permanente tensión y negociación en la construcción de las relaciones de género. Los indicios elusivos de resistencia nos parecen importantes para percibir relaciones de género dinámicas. Por una parte, en lo que podría pensarse como política exterior del reino, mujeres que eran parte del botín de guerra (elite femenina de casas rivales), ciertamente mujeres privilegiadas por su nacimiento, pero que eligen consagrarse a un dios como mecanismo de resistencia y logran cambios que parecían imposibles. Por otra, en el núcleo íntimo del reino, en las relaciones parentales más estrechas, algunas mujeres ponen en práctica mecanismos instituyentes que resquebrajan la rigidez de las relaciones de género, aunque la política matrimonial y los derechos del rey a disponer de hermanas e hijas no sean puestos en cuestión, él tiene en muchas circunstancias que volver sobre sus pasos y rever medidas naturalizadas por el uso. 


\section{Q Bibliografía}

» Abu-Lughod, L. (1990). The Romance of Resistance: Tracing Transformations of Power through Bedouin Women, en: American Ethnologist 17/1: 41-55.

»Barberon, L. (2009). Les documents d'archives des religieuses en Babylonie ancienne: usage, transmission et conservation, en: Briquel-Chatonnet, F., Fares, S., Lion, B. y Michel, C. (eds.), Femmes, cultures et sociétés dans les civilisations méditerranéennes et procheorientales d'hier à aujourd'hui. París: De Boccard, 273-288.

" Barberon, L. (2012). Les religieuses et le culte de Marduk dans le royaume de Babylone. Mémoires de NABU 14. París: SEPOA.

》Bidaseca, K. (2018). La revolución será feminista o no será: la piel del arte feminista descolonial. Buenos Aires: Prometeo.

»Butler, J. (2010). Marcos de guerra. Las vidas lloradas. Barcelona: Paidós.

»Butler, J. (2017). Cuerpos aliados y lucha política: hacia una teoría performativa de la asamblea. Buenos Aires: Paidós.

»Charpin, D. y Ziegler, N. (2003). Mari et le Proche-Orient à l'époque amorrite. Essai d'histoire politique. Florilegium Marianum V. Mémoires de NABU 6. París: SEPOA.

"De Graef, K. (1999). Les étrangers dans les textes paléobabyloniens tardifs de Sippar (Abi-ešuh - Samsuditana). ler partie : sur les inconnus "connus" : Cassites, Elamites, Sutéens, Suhéens, Gutéens et Subaréens, en: Akkadica III: 1-48.

»De Graef, K. (2016). Cherchez la femme! The Economic Role of Women in Old Babylonian Sippar, en: Lion, B. y Michel, C. (eds.), The Role of Women in Work and Society in the Ancient Near East. Berlín: Walter de Gruyter, 270-296.

»De Graef, K. (2018a). In Taberna Quando Sumus: On Taverns, Nadītum Women, and the Gagûm in Old Babylonian Sippar, en: Budin, S. L., Cifarelli, M., Garcia Ventura, A. y Millet Albà, A. (eds.), Gender and Methodology in the Ancient Near East: Approaches from Assyriology and Beyond. Barcelona: Edicions de la Universitat de Barcelona, 77-115.

"De Graef, K. (2018b). Puppets on a String? On Female Agency in Old Babylonian Economy, en: Svärd, S. y Garcia-Ventura, A. (eds.), Studying Gender in the Ancient Near East. University Park, Pennsylvania: Eisenbrauns-Penn State University Press, 133-156.

»Di Bennardis, C. (2013). La centralización del poder político y el estado en las sociedades antiguo-orientales: reflexiones sobre teorías e interpretaciones, en: Di Bennardis, C., Ravenna, E. y Milevski, I. (eds.), Diversidad de formaciones políticas en Mesopotamia y el Cercano Oriente. Organización interna y relaciones interregionales en la Edad del Bronce. Barcelona: Universidad de Barcelona, 1540.

»Dossin, G. (1950). Correspondence de Šamši -Addu et de ses fils. ARMT I. París: Imprimerie Nationale.

»Dossin, G. (1978 [1967]). Correspondance Féminine. ARM X. París: Librairie Orientaliste Paul Geuthner. 
»Driver, G. R. y Miles, J. C. (1952). The Babylonian Laws (2 vols.). Oxford: Clarendon Press.

»Durand, J.-M. (1997). Les documents épistolaires du palais de Mari. Tome I (LAPO 16). París: Les Éditions du Cerf.

»Durand, J.-M. (1998). Les documents épistolaires du palais de Mari. Tome II (LAPO 17). París: Les Éditions du Cerf.

"Durand, J.-M. (2000). Les documents épistolaires du palais de Mari. Tome III (LAPO 18). París: Les Éditions du Cerf.

» Durand, J.-M. y Margueron, J.-C. (1980). La question du harem royal dans le palais de Mari, en: Journal des Savants 4: 253-280.

»Fleming, D. (2004). Democracy's Ancient Ancestors: Mari and Early Collective Governance. Cambridge: Cambridge University Press.

»Foucault, M. (2008 [1976]). Historia de la sexualidad I. La voluntad del saber. México: Siglo XXI.

» Garcia-Ventura, A. (2012). El trabajo y la producción textil en la Tercera Dinastía de Ur. Tesis de Doctorado. Barcelona: Universitat Pompeu Fabra.

»Garrido, B. (2004). Feminismo, estudios de género y la visión performativa del género, en: Fernández, R., Buompadre, M., García, A. y Lovera, M. (comps.), IV Jornadas Nacionales de Historia Moderna y Contemporánea, 15 al 17 de septiembre de 2004, Universidad Nacional del Nordeste, Resistencia.

" Gelb, I. (1973). Prisoners of war in early Mesopotamia, en: Journal of Near Eastern Studies 32/1-2: 70-98.

»Guichard, M. (2009). Le remariage d'une princesse et la politique de Zimrî-Lîm dans la région du Haut Habur, en: Revue d'Assyriologie et d'archéologie orientale 103/1: 19-30.

» Harris, R. (1961). On the Process of Secularization under Hammurapi, en: Journal of Cuneiform Studies 15: 117-120.

» Harris, R. (1963). The Organization and Administration of the Cloister in Ancient Babylonia, en: Journal of the Economic and Social History of the Orient 6: 121-157.

» Harris, R. (1964). The Nadītu Women, en: Biggs, R. D. y Brinkman, J. A. (eds.), Studies Presented to A. Leo Oppenheim, June 7, 1964. Chicago: University of Chicago Press, 106-135.

" Harris, R. (1975). Ancient Sippar. A Demographic Study of an Old-Babylonian City (1894-1595 B.C.) (Publications de l'Institut historique-archéologique néerlandais de Stamboul 36). Leiden: Nederlands Instituut voor het Nabije Oosten.

» Heimpel, W. (2003). Letters to the Kings of Mari. Winona Lake: Eisenbrauns.

"Koschaker, P. (1917). Rechtsvergleichende Studien zur Gesetzgebung Hammurapis, Königs von Babylon. Leipzig: Veit \& Co.

»Laffont, R. (2001). Dictionnaire de la civilization mésopotamienne. París: Bouquins.

"Lafont, B. (2001). Relations internationales, alliances et diplomatie au temps des royaumes amorrites, en: Durand, J.-M. y Charpin, D. (eds.), Mari, Ébla et les Hourrites: dix ans de travaux, deuxiéme partie. París: Editions Recherche sur les Civilisations, 213-328.

"Lahtinen, S. (2011). The naditum as Businesswoman: Economic Enterprise among Religiously Devoted Women in Old Babylonian Sippar. Saarbrücken: Lambert 
Academic Publishing.

"Lévi-Strauss, C. (1993 [1949]). Las estructuras elementales del parentesco. Buenos Aires: Planeta-Agostini.

» Limet, H. (1995). L'émigré dans la société mésopotamienne, en: Van Leberghe, K. y Schoors, A. (eds.), Immigration and Emigration within the Ancient Near East: Festschrift E. Lipin'ski. Lovaina: Peeters, 165-179.

»Lion, B. (2007). La notion de genre en Assyriologie, en: Cuchet Sevillotte, V. y Ernoult, N. (eds.), Problèmes du genre en Grèce ancienne. Histoire ancienne et médievale 9o. París: Publications de la Sorbonne, 51-64.

»Mahmood, S. (2010). El sujeto de la libertad, en: Alcores: revista de historia contemporánea 10: 65-114.

» Marello, P. (1994). Esclaves et reines, en: Charpin, D. y Durand, J.-M., Recueil détudes à la mémoire de M. Birot. Florilegium Marianum II. Mémoires de NABU 3. París: SEPOA, 115-129.

" Michalowski, P. (1976). Royal Women of the Ur III period. Part I: the Wife of Šulgi, en: Journal of Cuneiform Studies 28: 169-172.

» Michalowski, P. (1979). Royal Women of the Ur III Period. Part II: Geme-Ninlila, en: Journal of Cuneiform Studies 31: 171-176.

" Michalowski, P. (1982). Royal Women of the Ur III Period. Part III, en: Acta Sumerologica 4: 129-142.

» Michalowski, P. (2011). The Correspondence of the Kings of Ur: An Epistolary History of an Ancient Mesopotamian Kingdom (Mesopotamian Civilizations 15). Winona Lake: Eisenbrauns.

" Oliver, M. R. (2008). Entre lechos, alianzas y alta política: las mujeres como botín de guerra durante del reinado de Zimrî-Lîm de Mari, en: Claroscuro 7: 11-34.

»Oliver, M. R. (2009). Relaciones políticas/relaciones de género en el antiguo reino de Mari a través de su correspondencia femenina. Análisis de un caso, en: III Jornadas Nacionales de Historia Antigua II Jornadas Internacionales de Historia Antigua, Universidad Nacional de Córdoba, 120-135.

"Oliver, M. R. (2013). Excluidas, confinadas y poderosas: las relaciones de género y el ejercicio del poder en Mari, en: Di Bennardis, C., Ravenna, E. y Milevski, I. (eds.), Diversidad de formaciones políticas en Mesopotamia y el Cercano Oriente. Organización interna y relaciones interregionales en la Edad del Bronce. Barcelona: Universidad Autónoma de Barcelona, 103-113.

»Oliver, M. R. y Ravenna, E. (1999). Matrimonio: ¿Contrato o alianza en la sociedad paleobabilónica? Apuntes para la reflexión, en: De Bernardi, C. y Díaz Molano, L. (eds.), Estado, sociedad y legalidad en la época hammurabiana. Rosario: Prohistoria, 99-115.

» Oliver, M. R. y Urbano, L. (2018). Mujeres reales entre lo instituido y lo instituyente: alianzas matrimoniales y política estatal en la Mesopotamia paleobabilónica, en: Garcia-Ventura, A. y Justel, J. J. (eds.), Las mujeres en el Oriente cuneiforme. Alcalá de Henares: Universidad de Alcalá, 347-374.

»Pateman, C. (1995 [1988]). El contrato sexual. México: Anthropos.

"Podany, A. (2010). Brotherhood of Kings. How International Relations Shaped the Ancient Near East. Oxford: Oxford University Press. 
»Reiner, E. (ed.). (1995 [1956]). CAD G= The Assyrian Dictionary of The Oriental Institute of the University of Chicago, Vol. 5. Chicago: Oriental Institute of the University of Chicago.

» Sasson, J. M. (2015). From the Mari Archives. An Anthology of Old Babylonian Letters. Winona Lake: Eisenbrauns.

"Segato, R. (2003). Las estructuras elementales de la violencia: ensayos sobre género entre la antropología, el psicoanálisis y los derechos humanos. Buenos Aires: Prometeo.

»Segato, R. (2016). La guerra contra las mujeres. Buenos Aires: Traficantes de Sueños/Tinta Limón.

"Seri, A. (2011). Domestic Female Slaves during the Old Babylonian Period, en: Culbertson, L. (ed.), Slaves and Households in the Near East. Chicago: The Oriental Institute of the University of Chicago, 49-67.

»Solvang, E. (2005). Classing Women: The “Harem" and What It Does and Doesn't Tell Us about Women, en: Biggs, R., Myers, J. y Roth, M. (eds.), Proceedings of the 51th Rencontre Assyriologique Internationale. Chicago: The Oriental Institute of the University of Chicago, 415-440.

»Spivak, G. C. (1988). Can the Subaltern Speak? Basingstoke: Macmillan.

»Stol, M. (2016). Women in the Ancient Near East. Berlín: W. de Gruyter.

"Stone, E. (1982). The Social Role of the Naditu Women in Old Babylonian Nippur, en: Journal of Economic and Social History of the Orient 25/1: 50-70.

"Svärd, S. (2012). Women, Power, and Heterarchy in the Neo-Assyrian Palaces, en: Wilhelm, G. (ed.), Organization, Representation and Symbols of Power in the Ancient Near East. Proceedings of the 54th Rencontre Assyriologique Internationaleat Würzburg 20-25 July 2008. Winona Lake: Eisenbrauns, 507-518.

"Svärd, S. (2015). Women and Power in Neo-Assyrian Palaces (SAAS 23). Winona Lake: Eisenbrauns.

"Urbano, L. (2011). Mujeres del rey. Críticas al concepto de harem desde la historia antiguo oriental, en: Zona Franca. Revista del Centro de Estudios Interdisciplinarios sobre Mujeres (CEIM) 20/XVIII: 155-167.

" Urbano, L. (2013). “Lo personal es político". Las alianzas matrimoniales como herramientas del poder político. Mari, SXVIII a.C, en: Di Bennardis, C., Ravenna, E. y Milevski, I. (eds.), Diversidad de formaciones políticas en Mesopotamia y el Cercano Oriente. Organización interna y relaciones interregionales en la Edad del Bronce. Barcelona: Universidad Autónoma de Barcelona, 115-129.

»Urbano, L. (2016). La política matrimonial mariota: un campo de poder entre la dominación y la resistencia. Mari (Tell Hariri) 1977-1962 a. C. Tesis doctoral inédita. Rosario: Universidad Nacional de Rosario.

»Urbano, L. (2018). Marriage Policy in Mari: A field of Power between Domination and Resistance. Some reflections from the Perspective of Gender, en: Svärd, S. y Garcia-Ventura, A. (eds.), Studying Gender in the Ancient Near East. University Park, Pennsylvania: Eisenbrauns-Penn State University Press, 423-445.

» Verderame, L. (2013). ¿Un pueblo imaginario? La creación de la identidad amorrea en los estudios asiriológicos, en: Di Bennardis, C., Ravenna, E. y Milevski, I. (eds.), Diversidad de formaciones políticas en Mesopotamia y el Cercano Oriente. Organización interna y relaciones interregionales en la Edad del Bronce. Barcelona: Universidad Autónoma de Barcelona, 41-55. 
»Westbrook, R. (1988). Old Babylonian Marriage Law (AfO, Beiheft 23). Horn: Berger.

»Westenholz, J. G. (1990). Towards a New Conceptualization of the Female Role in Mesopotamian Society, en: Journal of the American Oriental Society 110: 510521.

"Ziegler, N. (1999a). La population fémenine des palais d'après les Archives Royales de Mari. Le harem de Zimrî-Lîm. Florilegium Marianum IV. (Mémoires de N.A.B.U. 5). París: SEPOA.

»Ziegler, N. (1999b). Le harem du vaincu, en: Revue d'Assyriologie et d'archéologie orientale 93: 1-26.

»Ziegler, N. (2007). La musique et les musiciens d'après les archives royales de Mari. Florilegium Marianum IX. (Mémoires de N.A.B.U. 10). París: SEPOA. 
